\title{
The Synthesis of Glycerol Carbonate from Biodiesel Byproduct Glycerol and Urea over Amberlyst 36
}

\author{
Astri Senania ${ }^{\varpi}$, Hary Sulistyo, Agus Prasetya \\ DOI 10.15294/jbat.v6i1.7691 \\ Departemen Teknik Kimia, Fakultas Teknik, Universitas Gadjah Mada \\ J1. Grafika No. 2, Yogyakarta, 55281
}

\begin{tabular}{l} 
Article Info \\
\hline Article history: \\
Accepted \\
November 2016 \\
Approved \\
April 2017 \\
Published \\
June 2017 \\
\hline Keywords : \\
Amberlyst 36; \\
Glycerol; \\
Glycerol Carbonate; \\
Urea \\
\hline
\end{tabular}

\begin{abstract}
The increasing use of biodiesel as renewable fuels leads to the increasing of glycerol amount as a byproduct of biodiesel production. One of the glycerol derivative products that is environmentally friendly and renewable is glycerol carbonate. Glycerol carbonate is commonly used as a raw material for polymers, surfactants, emulsifiers, lubricants, paints, also used in the cosmetics and pharmaceutical industries. In this study, the research was carried out by using a batch reactor with a three-neck flask equipped with reverse cooling, thermometers, mercury stirrer, and heating mantle with the conditions of the reaction temperature around $373-413 \mathrm{~K}$, mole ratio of reactants of urea: glycerol were 1:0,5, 1:1, $1: 1,5,1: 2$ and $1: 4$ and the concentration of catalyst were $1 \%, 2 \%, 3 \%, 4 \%$ and $5 \%$ respectively. Reaction was done for four hours. The results showed that the formation of glycerol carbonate from glycerol and urea using a catalyst Amberlyst 36 is affected by the catalyst concentration, reaction temperature and the ratio of reactants used. The highest glycerol conversion was obtained at $55.07 \%$ at a temperature of $393 \mathrm{~K}$ with mole ratio of urea and glycerol 1:0,5 and the percentage of catalyst $3 \%$ of the amount of glycerol.
\end{abstract}

\section{INTRODUCTION}

Biodiesel is one of potential alternative fuel to be developed in Indonesia. It is commonly produced through transesterification process of vegetable oil using methanol in the presence of catalyst. Biodiesel production from triglycerides will generate about $10 \%(\mathrm{v} / \mathrm{v})$ glycerol as main byproduct. The surplus of glycerol from biodiesel production become research focus to find an innovative way to transform glycerol into more valuable product. One of this solution is to utilize glycerol as raw material of glycerol carbonate production.

Glycerol carbonate is a non-toxic, nonflammable, possess low vapor pressure, high boiling point and also moisturizing ability. Glycerol has many applications in industrial sector, it can be used as raw material for production of polymer, surfactant, emulsifier, adhesive, ink, lubricant, paint, intermediates in cosmetics and pharmaceutical industries.

Glycerol carbonate can be synthesized through (1) glycerol carboxylation with urea (2) glycerol carboxylation with carbonate sources such as ethylene carbonate or dimethyl carbonate, and (3) supercritical reaction of glycerol with carbon dioxide. Glycerol supercritical reaction with carbon monoxide catalyzed by $\mathrm{n}-\mathrm{Bu}_{2} \mathrm{Sn}(\mathrm{OMe})_{2}$ only produce glycerol carbonate with $5.72 \%$ yield. Supercritical process from previous study which is performed at high temperature and pressure still has not give optimum result (Aresta et al., 2006). Li \& Wang (2011) stated that to obtain sufficiently high

\footnotetext{
${ }^{\square}$ Corresponding author:

Departemen Teknik Kimia, Fakultas Teknik, Universitas Gadjah Mada

Jl. Grafika No. 2, Yogyakarta, 55281

E-mail: ugmchemist_3@yahoo.com
} 


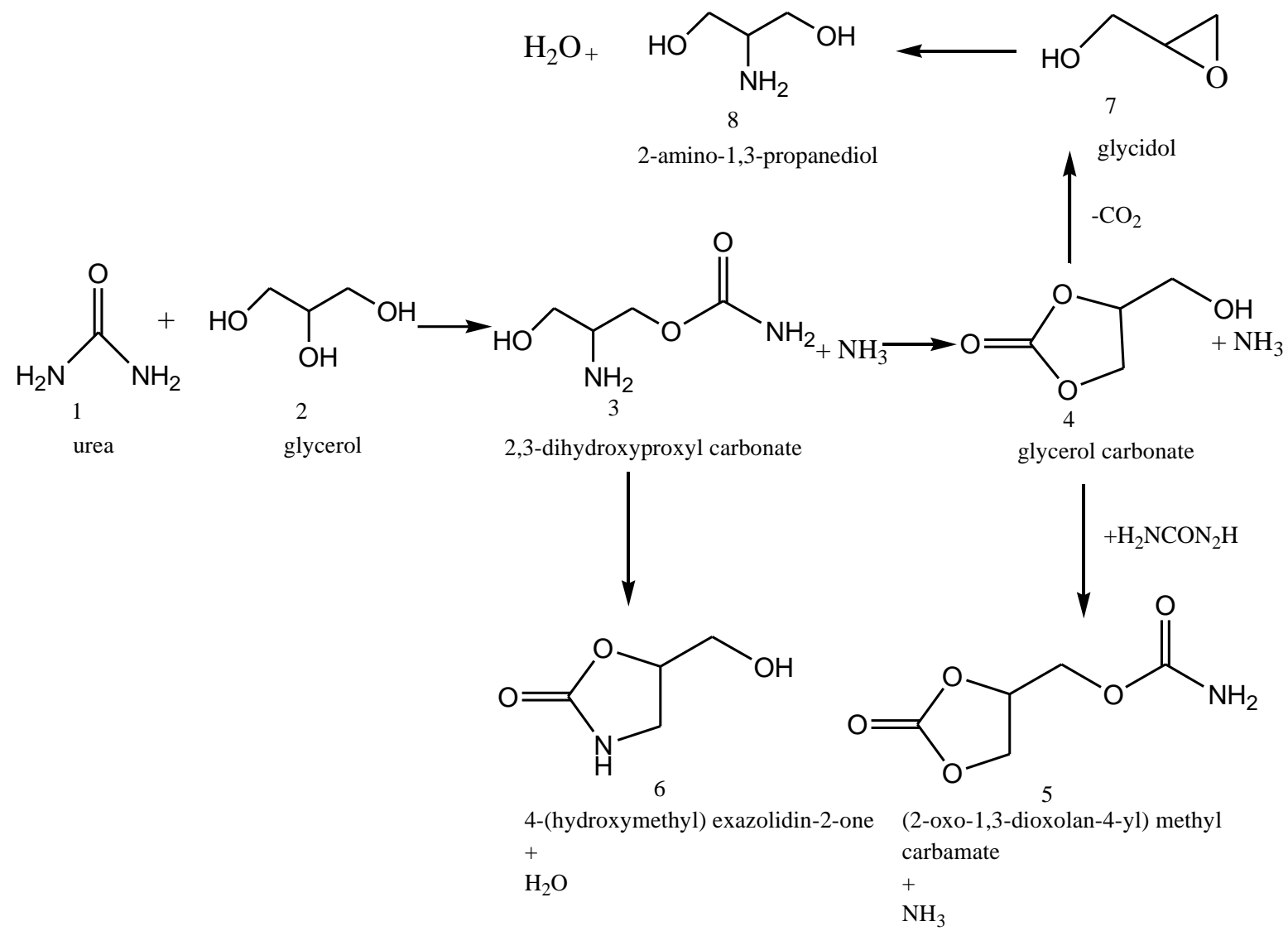

Figure 1. Possible reaction pathways for the reaction between glycerol and urea.

yield of glycerol carbonate need to be separated which require high energy. Reactant recycle process also favor high cost.

There are several reaction steps in producing glycerol carbonate from glycerol and urea. Zhang \& He (2014) propose reaction steps of glycerol with urea as shown in Figure 1. Glycerol and urea is reacted to produce intermediate which might produce byproduct beside glycerol carbonate. Glycerol carbonate also able to react with the reactants to produce another byproduct.

The disadvantages of preparing glycerol carbonate from glycerol and urea lead to creation of large amounts of ammonia, which need to be separated to avoid interference during reaction process (Claude et al., 2001). According to Aresta et al. (2009) removal of ammonia during process can be done by reacting ammonia produced with carbon monoxide to produce urea. Moreover, glycerol carbonate production from carboxylation of glycerol with urea uses easily available and low cost material.

In this paper, factors affecting production of glycerol carbonate from reaction between glycerol and urea over cationic resin solid catalyst
Amberlyst 36 are studied. Ion exchanger solid catalyst is used in this research due to its advantages such as ease of separation and reusability. Saturated solid catalyst can be easily regenerated (Choi et al., 1996). Amberlyst 36 has been used by several researcher such as Akbay \& Altiokka (2011) which evaluates the kinetic and thermodynamic equilibrium of acetic acid esterification process with n-amyl alcohol using this catalyst. Experimental results showed that surface reaction kinetics is the determining step and temperature affects chemical equilibrium.

\section{MATERIALS AND METHODS}

\section{Materials}

Glycerol (98\%) with density of $1.257 \mathrm{~g} / \mathrm{ml}$ was supplied by PT. Brataco Chemical Yogyakarta, Urea (98.57\%). Amberlyst 36 activated by HCL 6 M.

\section{Experimental setup}

Experimental setup used in this research is shown in Figure 2. 


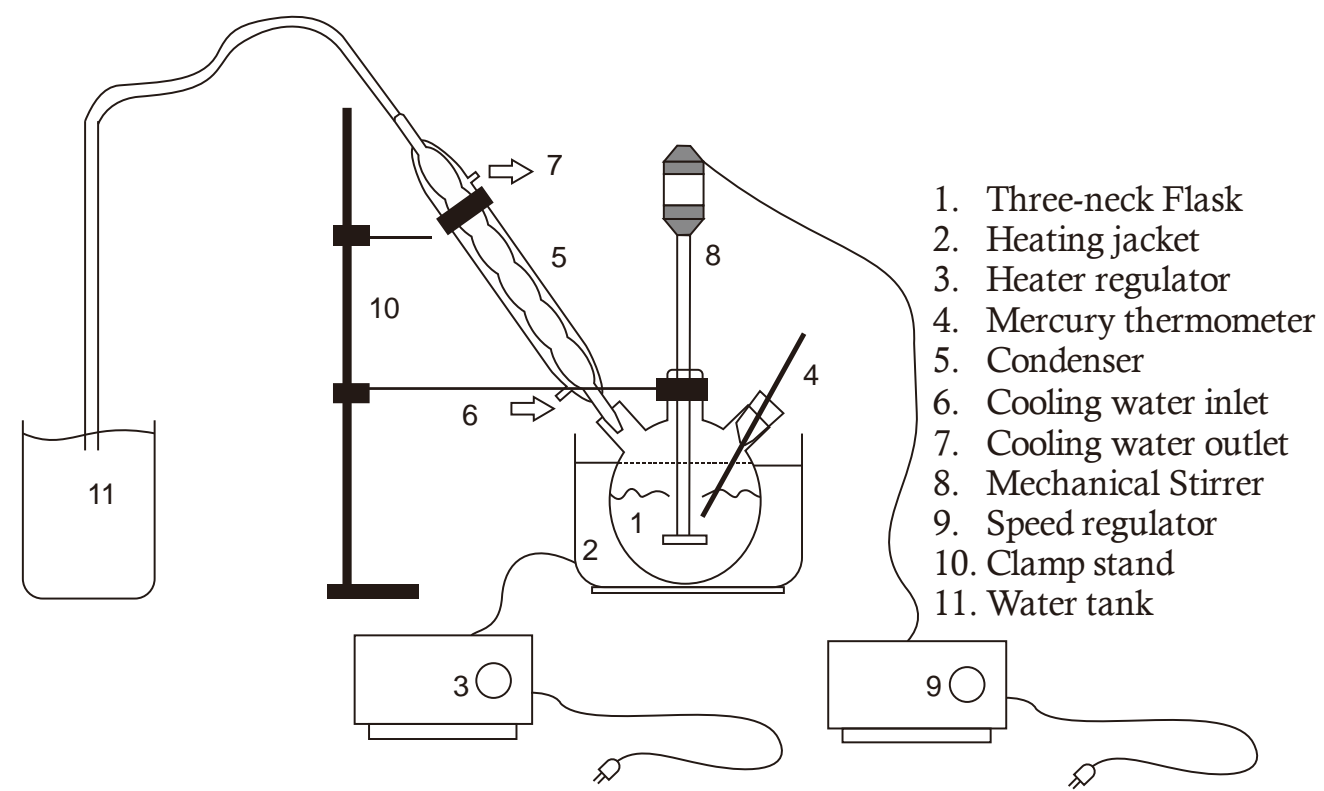

Figure 2. Experimental setup of glycerol carbonate production.

\section{Synthesis of Glycerol Carbonate}

Glycerol and amberlyst 36 catalyst based on research variable were put inside three-neck flask. Cooling water then turned on and magnetic stirrer was set to the scale of $375 \mathrm{rpm}$. Next, heater was turned on. After it reached the desired temperature, urea was then poured till it mixed well. Sample then gradually taken every 30 minutes for 4 hours at different temperature variable. Once sampling process is finished, heater and magnetic stirrer were turned off. Subsequently, cooler was turned off after temperature getting lower. Samples were then analyzed using titration method to measure free glycerol concentration. The experimental procedures were then repeated for each variable.

\section{Research Variable}

This research was conducted at temperature of $373-413 \mathrm{~K}$. Urea : glycerol molar ratios used were 1:0.5, 1:1, 1:1.5, 1:2 and 1:4, amberlyst 36 concentration (\%wt) used was $1 \%$, $2 \%, 3 \%, 4 \%$ and $5 \%$ under constant stirring (375 rpm).

\section{Product Analysis}

Quantitative analysis of free glycerol in glycerol carbonate was determine by titration with sodium thiosulfate $\left(\mathrm{Na}_{2} \mathrm{~S}_{2} \mathrm{O}_{3}\right)$. Glycerol conversion was calculated by substracting starting glycerol with free glycerol and dividing it by the starting glycerol. Subsequently, urea conversion can be calculated.
Qualitative analysis were performed by using GCMS.

\section{RESULTS AND DISCUSSIONS}

Parameters studied in this research were weight of catalyst, reaction temperature and reactant molar ratio to the synthesis of glycerol carbonate.

\section{Effect of Catalyst Weight}

The effect of glycerol conversion was investigated in a range of $1-5 \%$ (\%wt). Other parameters were set at constant temperature $393 \mathrm{~K}$ and urea to glycerol molar ratio $1: 1$ with reaction time for 4 hours.

Figure 3 shows that increasing of catalyst loading led to gradual increase in glycerol carbonate conversion. In other words, catalyst addition will increase rate of reaction. The use of $5 \%$ catalyst loading gave highest glycerol conversion at $43.48 \%$.

The increasing of glycerol conversion at catalyst loading $3-5 \%$ is less significant compared to catalyst loading 1-3\%. This is due to active sites of catalyst needed by reactant almost reached its maximum limit.

This results were in line with study of glycerol carbonate production from glycerol and urea in the presence of $\mathrm{Ni} / \gamma \mathrm{Al}_{2} \mathrm{O}_{3}$ catalyst investigated by Damayanti et al. (2012). The research was conducted by varying $\mathrm{Ni} / \gamma \mathrm{Al}_{2} \mathrm{O}_{3}$ catalyst loading to 1,3 and $5 \%$ (\%wt glycerol). The 


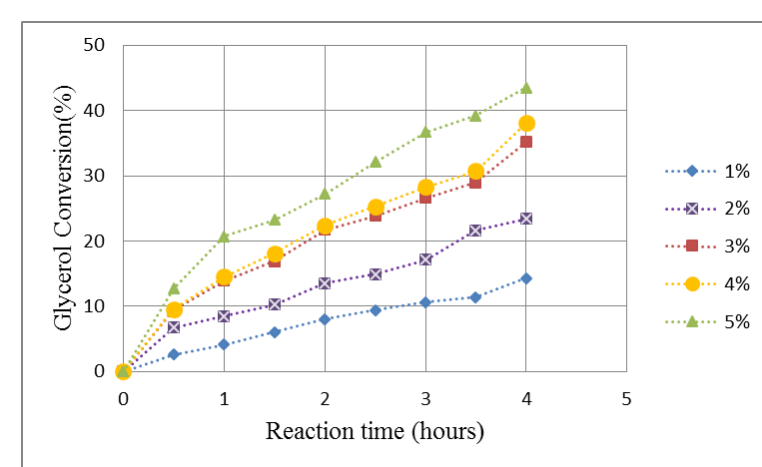

Figure 3. Glycerol conversion in function of reaction time at different catalyst loading.

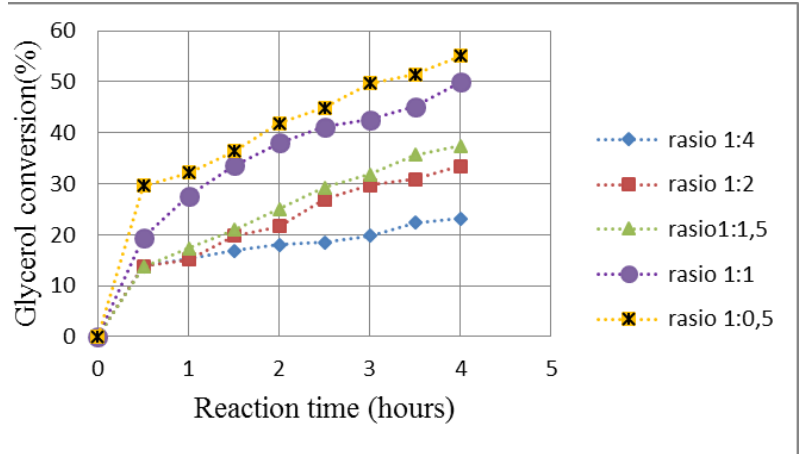

Figure 4. Glycerol conversion in function of reaction time at different urea : glycerol molar ratio.

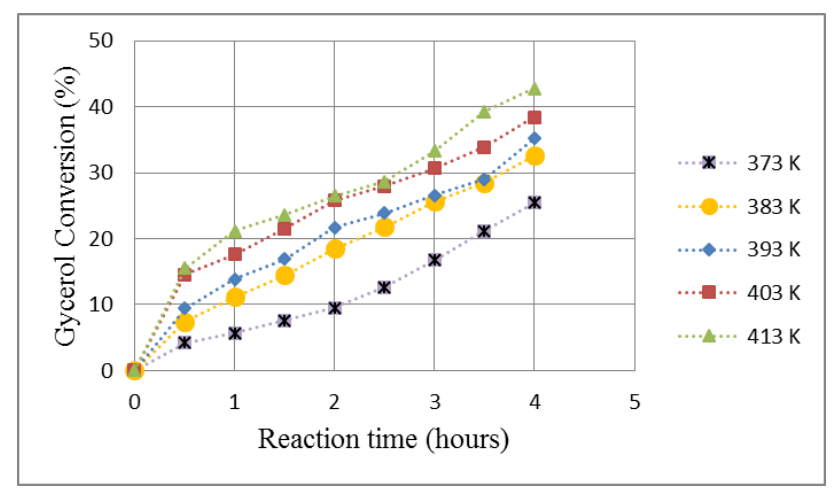

Figure 5. Glycerol conversion in function of reaction time at different reaction temperature.

best result was obtained at $5 \%$ catalyst loading with glycerol conversion and glycerol carbonate 43.93 and $27.83 \%$ respectively at operating temperature $423 \mathrm{~K}$.

\section{Effect of Reactant Molar Ratio}

Figure 4 shows that higher urea : glycerol molar ratio leads to higher glycerol conversion. The highest glycerol conversion obtained at molar ration of $1: 0.5$ at constant $3 \%(\% \mathrm{wt})$ of catalyst loading and temperature of $393 \mathrm{~K}$. At this condition we achieve $55.07 \%$ glycerol conversion. Higher urea to glycerol molar ratio allows more carbonyl groups produced, so that reaction between glycerol glycerol and urea will produce glycerol carbonate easily (Zhang \& He, 2014). This results is supported by Hammond et al. (2011) statement, when urea becomes limiting reactant there is not enough urea used in reaction with consequence of reducing glycerol conversion.

\section{Effect of Temperature}

Figure 5 shows the effect of temperature to glycerol conversion for 4 hours reaction time. Increasing reaction temperature, lead to dramatic effect towards glycerol conversion. Particles kinetic energy will be higher at high temperature resulting increasing of particle collision and faster reaction process. In this research, highest glycerol conversion obtained at reaction temperature of 413 $\mathrm{K}$ with 42.75 glycerol conversion.

\section{CONCLUSION}

In this study, it can be concluded that glycerol production is affected by reaction temperature, urea to glycerol molar ratio and also catalyst weight. Highest glycerol conversion in this research was $55.07 \%$ obtained at $393 \mathrm{~K}$ reaction temperature, urea to glycerol molar ratio of 1:0.5 and 3\% (\%wt) catalyst loading to the amount of glycerol.

\section{REFERENCES}

Aresta, M. Dibenetto, A. Nocito, F. Pastore, C., 2006, A Study on the Carboxylation of Glycerol to Glycerol Carbonate with Carbon Dixide : the Role of Catalyst, Solvent and Reaction Condition, Journal of molecular catalysis $257: 149-153$.

Aresta, M. Dibenetto, A. Nocito, F. Ferragina, C., 2009, Valorization of Bio-Glycerol : New Catalytic Materials for the Synthesis of 
Glycerol Carbonate Via Glycerolysis of Urea, Journal of Catalysis 268 : 106-114

Claude, S., Moulongui, Z., Yoo, J.W., and Gasset, A., 2001, "Method for preparing glycerol carbonate", European Patent No. 0955298 B1

Choi, J. I., Hong, W. H., Cham, H.N., 1996. Reaction Kinetics of Lactic Acid with Methanol Catalyzed by Acid Resins, Int.J. Chem. Kinet. 28, 37-41.

Damayanti, O., Gustanti, Y., Roesyadi A., 2012, Pembuatan Gliserol Karbonat Dari Gliserol Dengan Katalis Berbasis Nikel, Jurnal Teknik ITS, Vol. 1, No. 1, ISSN : 2301-9271

Dasari, M.A., P.P. Kiatsimkul, W.R. Sutterlin, G.J. Suppes, 2005, Low-Pressure Hydrogenolysis of Glycerol to Propylene Glycol, Journal Applied Catalysis A : General 281(1-2): 225-231

Hammond, C., Sanchez, J. A. L., Rahim, M. H. A., Dimitratos, N., Jenkins, R.L., Carley,
A.F., He, Q., Kiely C. J., Knight, D.W., Hutchings G. J., 2011, Synthesis of Glycerol Carbonate from Glycerol and Urea with Gold-Based Catalysts, The Royal Society of Chemistry, 40 : 3927-3937

Li, J., Wang, T., 2011, Chemical Equilibrium of Glycerol Carbonate Synthesis from Glycerol, Journal of Chemical Thermodynamics, Vol. 43, page 731-736

Akbay, E. Ö., Altiokka, M. R., 2011, Kinetics of Esterification of Acetic Acid with n-Amyl Alcohol in the Presence of Amberlyst-36, Journal Applied catalysis 396 : 14-19

Pagliaro, M., Rossi, M., 2008, The Future of Glycerol: New Uses of $A$ Versatile Raw Material, RSC Green Chemistry Book Series, Cambridge

Zhang, J., He, D., 2014, Lanthanum-Based Mixed Oxides for The Synthesis of Glycerol Carbonate from Glycerol and Urea, Reac. Kinet. Mech. Cat., 10 